\title{
AVALIAÇÃO DOS EFEITOS DO PASTOREIO SOBRE A EROSÃO EM MARGENS DE CANAL FLUVIAL EM SISTEMA DE FAXINAL
}

\section{Assessment of the grazing efects on the river bank erosion in faxinal system}

\author{
Wolliver Anderson Dias \\ Graduação em Geografia - UNICENTRO \\ Mestrado em Gestão do Território da (UEPG) \\ Guarapuava/PR - Brasil \\ wollivergeo@yahoo.com.br \\ Edivaldo Lopes Thomaz \\ Doutor em Geografia Física - Universidade de São Paulo \\ Professor Adjunto da UNICENTRO \\ Guarapuava/PR - Brasil \\ ethomaz@brturbo.com.br
}

Artigo recebido para publicação em 31/10/2010 e aceito para publicação em 06/04/2011

RESUMO: O Brasil possui grande quantidade de áreas destinadas a pastagens, de modo que tal atividade influência consideravelmente nos processos geomorfológicos. O presente trabalho buscou avaliar os efeitos do pastoreio na erosão de margens de rio em áreas de Faxinal no município de Guarapuava - PR. Para isso, avaliados foram os aspectos fisicos das margens, bem como, utilizou-se de técnicas volumétricas e de avaliações na geometria do canal para se constatar a influencia do pastoreio sobre a erosão. Observou-se que o gado acelerou significativamente os processos geomorfológicos nas zonas ripárias, portando-se como importante agente modelador da paisagem.

Palavras-chave: Pastoreio. Erosão de margens. Sistema de faxinal.

ABSTRACT: Brazil has a lot of pastureland areas. The cattle grazing have influences on the geomorphological processes. This study evaluated the effects of grazing on river banks erosion in Faxinal areas in Guarapuava - PR. It was evaluated the effects of livestock on the river bank physical properties. Also, it was used volumetric and channel geometry technique in order to observe the grazing influence on soil erosion. It was observed that livestock has significantly accelerated the geomorphological processes in riparian zones. Consequently, the cattle have been an important agent on the landscape shaping.

Keywords: Grazing. River bank. Erosion. Riparian zone. Faxinal system. 


\section{INTRODUÇÃO}

A ocupação do solo vem ganhando cada vez mais destaque no meio científico, devido aos reflexos oriundos de tal ocupação e a importância deste recurso enquanto condicionante da vida humana. Observa-se no cenário atual a crescente expansão de áreas a se dedicar as atividades agropecuárias, o que torna também crescente a quantidade de problemas ambientais associados à degradação de solos.

Tanto as atividades agrícolas como as pecuárias merecem atenção do ponto de vista geomorfológico, pois ambos os usos influenciam diretamente nos processos erosivos e nas formas da paisagem.

Neste contexto, ressalta-se a influencia dos efeitos do pastoreio sobre as propriedades do solo e por extensão nos processos geomorfológicos, os quais passaram a ser maiores no Brasil nos últimos anos, devido ao aumento de áreas destinadas à pecuária. A análise de dados do IBGE indicou que no período entre os anos de 1990 a 2005, o Brasil atingiu um crescimento anual de $2,11 \%$ no crescimento do rebanho bovino, de modo que algumas regiões superaram a taxa de crescimento nacional, como foi o caso das regiões Centro-Oeste e Norte, enquanto que as regiões Sul, Sudeste e Nordeste apresentaram taxas inferiores as nacionais, sendo este o resultado da expansão ou esgotamento da fronteira agropecuária em cada uma das regiões (THOMAZ; DIAS 2009). Os autores destacam ainda um aumento na taxa anual nas pastagens plantadas para o Brasil na ordem de $1,1 \%$ entre os anos de 1970 a 1996.

Os efeitos do pastoreio nos processos geomorfológicos já foram tratados por diversos pesquisadores, entretanto, são poucos os trabalhos com tal enfoque no Brasil.

Para Thomaz e Dias (2009) o pastoreio resulta em efeitos de ordem direta e indireta, além disso, afetam diferentes partes dos sistemas geomorfológicos como: as partes altas das vertentes (terras altas) e as zonas ripárias (terras baixas).

Evans (1998) afirma que o pastoreio aumenta a densidade do solo, a taxa de erosão aumenta, o escoamento superficial induz a formação de sulcos e ravinas. Essa modificação biofísica (solo exposto, compactação, escoamento, ravinamentos) em áreas de pastagens, também foi confirmada por Thomaz (2005). Thomaz e Dias (2009), a partir de testes realizados com Penetrômetro de Impacto Modelo IAA/ Planalsucar-Stolf, verificaram que a resistência entre 0-5 cm (topo do solo) é bem superior em comparação com as demais profundidades (decréscimo exponencial). Os autores afirmam que dentro de uma mesma pastagem os efeitos do pisoteio do gado resultaram em resistência e compactação do solo distinta, criando diferentes ambientes (heterogeneidade). Deste modo, nas trilhas do gado onde os animais passam constantemente a compactação superficial é muito alta, com um impacto houve um aprofundamento de $2,7 \mathrm{I} / \mathrm{cm}$ (Impacto/cm) da sonda $\left(\mathrm{r}^{2} 98,9 \%\right.$, coeficiente de determinação). Na pastagem adjacente às trilhas do gado um impacto resultou em $3,23 \mathrm{I} / \mathrm{cm}$ de penetração da sonda ( $\left.\mathrm{r}^{2} 87,2 \%\right)$, ou seja, a resistência foi $20 \%$ inferior. Já, as áreas de pastagens no interior de floresta secundária a resistência foi bem inferior $3,87 \mathrm{I} / \mathrm{cm}\left(\mathrm{r}^{2}\right.$ $68,3 \%$ ), isto é, $43 \%$ inferior à resistência registrada nas trilhas e $20 \%$ inferior as áreas adjacentes às trilhas.

Inicialmente a resistência entre a pastagem e a pastagem no interior da floresta foi igual, pois nestas áreas com um impacto houve um aprofundamento da sonda de $9,86 \mathrm{~cm}$ (C.V 18,9\%) e 9,57 cm (19,9\%) respectivamente. Isso indica que mesmo no interior de floresta com pastoreio o topo do solo se apresentou compactado. A partir dos $15 \mathrm{~cm}$ de profundidade houve diferenciação no padrão de resistência nas duas áreas. Pois, em profundidade maior ocorre o aumento de raízes que dificulta o adensamento do solo (mais vazios) (THOMAZ; DIAS 2009).

Nas terras baixas (zonas ripárias), os efeitos do pastoreio apresentam-se de forma expressiva. Vários estudos indicam uma preferência de pastoreio do gado pelas zonas ripárias devido a maior disponibilidade de forragem, proximidade da água e condições de conforto térmico entre outros aspectos. Por causa dessa preferência as zonas ripárias acabam sofrendo superpastejo (THOMAZ; DIAS 2009).

Os efeitos do pastoreio sobre às zonas ripárias, apresenta um grande potencial de degradação, pois o gado remove a vegetação da margem dos rios, deixando o solo exposto a atuação dos processos erosivos. As pastagens são mais prejudiciais aos ambientes aquáticos que áreas cultivadas, pois contribuem signi- 
ficativamente para o assoreamento dos cursos d'água (YANKEY et al. 1991 apud WOHL; CARLINE 1996). Dessa forma, o tipo de cobertura do solo é particularmente importante na prevenção de erosão, pois sob condições naturais toda a formação vegetal (copas das árvores, sub-bosque e serrapilheira) atua de forma a amortecer a energia da água vinda da chuva (SILVA et al. 2003 apud FERREIRA; CASATTI, 2006).

Os efeitos do pastoreio aparecem de duas maneiras nas zonas ripárias, pela modificação direta do canal fluvial e margens (ruptura mecânica), e indireta por meio da redução da resistência do material (canal e leito) promovendo a erosão do canal (TRIMBLE; MENDEL, 1995).

Trabalhos realizados no Japão indicam que atividades de pastagem próximas às zonas ripárias causam uma perda de habitats aquáticos e terrestres, e os ecossistemas do rio foram severamente danificados. Zonas ripárias japonesas têm sofrido o mesmo destino que os rios. Eles têm sido afetados pelo desenvolvimento das pastagens na bacia superior, devido à deposição de sedimentos finos e nutrientes (NAKAMURA et al., 1997 apud NAKAMURA; YAMADA, 2005).

As áreas onde as pastagens se dispõem em meio às zonas ripárias apresentam maior susceptibilidade à degradação, assim, o uso da terra em sistema de faxinal tornam-se propicio para ocorrência de tal fenômeno. O Faxinal se constitui num sistema de uso e apropriação das terras. É uma organização socioeconômica rural, que expressa um modelo peculiar de vida que foi adotado, inicialmente, por comunidades rurais de um Brasil Caboclo. Hoje, tais comunidades incluem também descendentes de imigrantes europeus, vivendo em torno das atividades silvos-pastoris praticadas num Criadouro comum. Neste não há cercas divisórias e os animais (gado) andam misturados e livres entre as árvores de uma mata quase sempre bem preservada. Ali também se localizam as suas casas (LÖWEN SAHR; CUNHA, 2005; LÖWEN SAHR; IEGELSKI ,2003 apud FLORIANI et al., 2010).

A Bacia do Rio Guabiroba (Figura 1), localizada no município de Guarapuava/PR - Brasil, tem o uso da terra como um dos principais elementos controladores de sua dinâmica hidrológica. Haja vista, a grande diversidade de usos, reflorestamento, agricultura convencional mecanizada, agricultura de subsistência, pastagens, depressões úmidas, estradas, caminhos, etc. Essa diversidade forma um verdadeiro mosaico espacial e, por conseguinte, confere a cada uma dessas unidades de paisagens comportamento peculiar, mas que no conjunto global se reflete na dinâmica hidrogeomorfológica (THOMAZ, 2005).

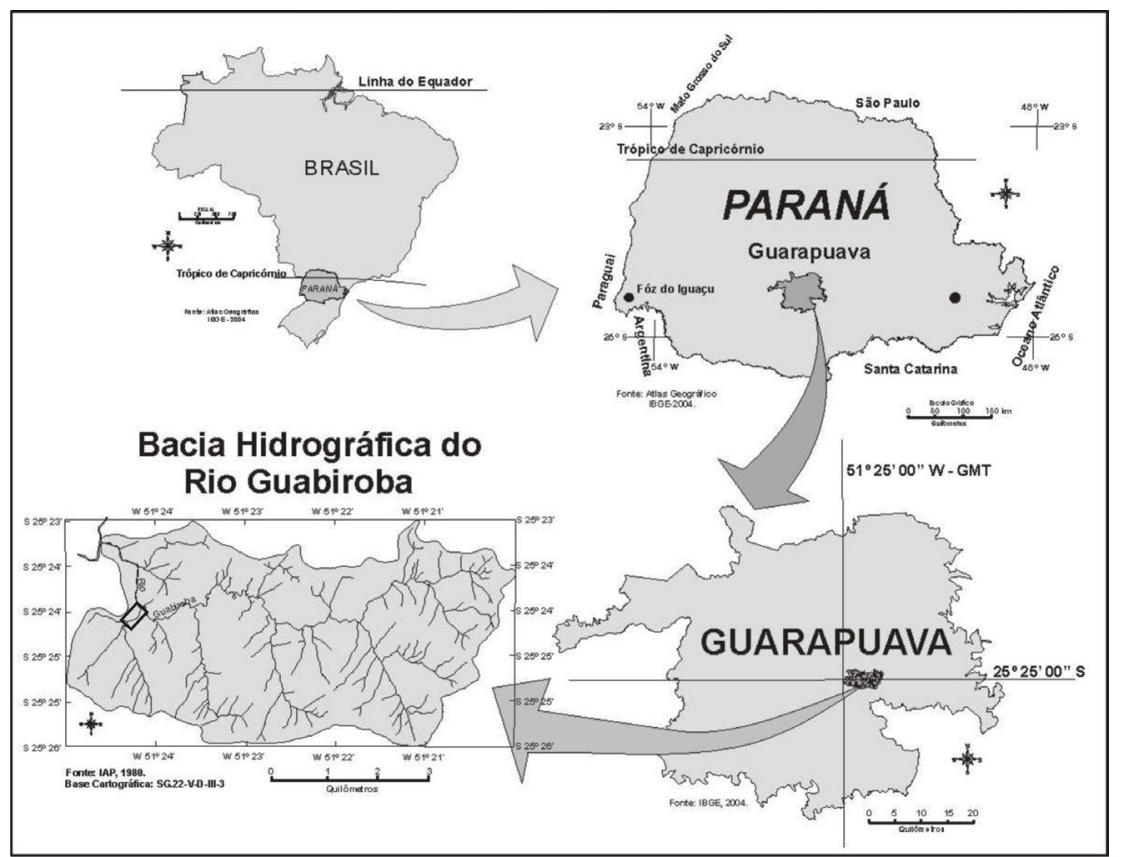

Figura 1: Localização da área de estudo no âmbito da bacia do Rio Guabiroba (quadro: setor de canal fluvial monitorado) 
A Bacia do Rio Guabiroba possui uma extensão de $23,7 \mathrm{Km}^{2}$, dos quais $33,10 \%$ são ocupados por pastagem, sendo esta, a segunda maior forma de uso. Este uso aparece em todos os setores da bacia, bem como nas diferentes unidades geomorfopedológicas, e por extensão, é praticado em declividade menor do que $12 \%$ até declividade superior a $40 \%$ (Thomaz, 2005). A propriedade onde fora realizada a pesquisa, possuí em média 60 cabeças de gado (bovino e ovino) distribuídos em pastagem ao longo de um canal (afluente da margem esquerda do Rio Guabiroba) de terceira ordem (STRAHLER, 1957) em um sistema de Faxinal (Floresta Ombrófila Mista).

Assim, o presente experimento teve por objetivo avaliar os efeitos do pastoreio sobre a erosão em margens de canal fluvial em área de Faxinal. Para tanto, buscou-se comparar os aspectos físicos das margens em áreas com e sem efeito do pastoreio; avaliar a dinâmica da erosão em trechos de influência do pastoreio por meio de técnicas volumétricas e; constatar a influência do gado na geometria do canal.

\section{MATERIAIS E MÉTODOS}

Os aspectos físicos dos solos avaliados nas margens do rio onde ocorre e não ocorre efeito do pastoreio foram: Resistência $\left(\mathrm{Kgf} / \mathrm{cm}^{2}\right)$; Densidade do solo $\left(\mathrm{g} / \mathrm{cm}^{3}\right)$ e; Porosidade Total (\%). Para se avaliar a resistência (compactação) do solo nas margens do canal, foi utilizado penetrômetro de bolso (Pocket Soil Penetrometer H-4200). Este equipamento determina a resistência de compressão e avalia a capacidade de suporte por meio de penetração de uma haste no material avaliado. $\mathrm{O}$ aparelho registra resistência de até $4,5 \mathrm{kgf} / \mathrm{cm}^{2}$. Foram coletadas 90 amostras em margens onde ocorre o efeito do pastoreio e 90 amostras onde tal efeito é ausente (a montante e a jusante dos locais de travessia do gado). Após a coleta utilizou-se estatística descritiva e de inferência para análise dos dados.

$\mathrm{Na}$ avaliação da densidade e porosidade superficial do solo, foram utilizados anéis volumétricos para retirada de amostras indeformadas do solo das margens do canal nas diferentes áreas, ou seja, com e sem efeito do pastoreio. Deste modo, foram coletadas 14 amostras, $7 \mathrm{em}$ locais onde ocorre efeito do pastoreio e 7 onde não ocorre. Em seguida, no laboratório, as amostras retiradas em campo foram pesadas e levadas para secar em estufa à $105^{\circ} \mathrm{C}$ por 24 horas (Embrapa, 1997). Posteriormente, após a secagem o material foi novamente pesado e os valores de densidade e porosidade dos solos analisados foram obtidos segundo (REICHARDT, 1990).

Em relação às áreas afetadas pelo gado foram utilizadas técnicas de monitoramento de margens (erosão e geometria do canal), adaptadas a partir de Lawler (1993) e Thomaz e Luiz (2004). Foi utilizada a técnica de mensuração volumétrica denominada de perfil/seção transversal (cross profile). Estacas fixas foram instaladas às margens do canal, contudo, fora do caminho de travessia do gado. Em seguida um barbante ligando uma margem à outra do canal foi disposto transversalmente sobre os fios sustentados pelas estacas. O quadro formado pelas estacas de referências serviu de nível planimétrico (Figura 2). Posteriormente, realizou-se a mensuração com uma trena metálica fixada em uma estaca de madeira. A mensuração foi realizada em intervalos fixos (1 m de distância). Assim, pôde-se avaliar o rebaixamento e mudança na forma do leito do canal, por meio da comparação dos perfis mensurados em diferentes datas. 


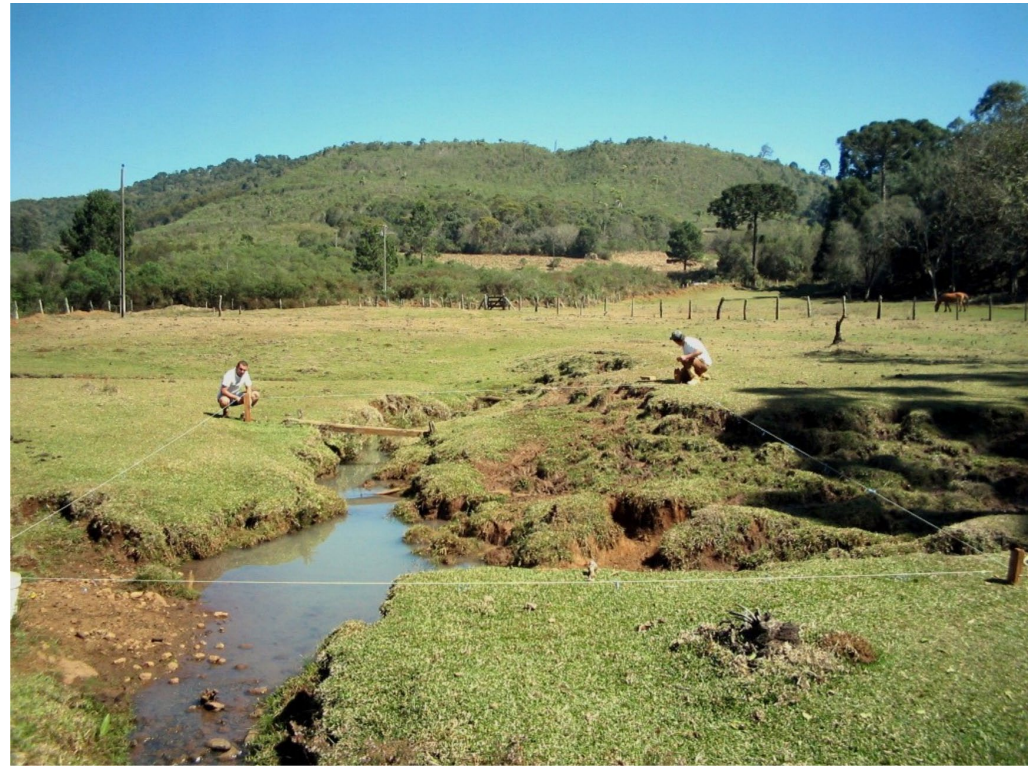

Figura 2: Quadro formado por quatro estacas de referências para monitoramento da erosão (visão geral da seção 1).

No monitoramento conduzido foram instaladas 3 seções para avaliação da erosão e mudança de geometria no leito do canal. As mensurações das seções foram realizadas ao longo de 28 meses. A técnica de perfis transversais repetidos (repeated cross profiling) possui aplicação de monitoramento em escala intermediária de tempo superior a 10 anos, enquanto a resolução varia entre poucos dias a um mês, ou seja, a erosão ou modificação na geometria só pode ser obtida a partir de um tempo (resolução), desde a instalação da rede de monitoramento (LAWLER 1993).

Após a obtenção dos dados de monitoramento realizou-se um material cartográfico para representar as seções comparadas entre o início e o termino do monitoramento. Utilizou-se o programa SURFER 8.0 .

A estimativa de remoção ou acúmulo de material foi obtida por meio da equação abaixo.

Equação 1 - Avaliação da remoção do solo

$$
\mathrm{E}=\mathrm{R} \times \mathrm{Ds}
$$

$\mathrm{E}=$ Erosão ou acúmulo de solo $\left(\mathrm{kg} \mathrm{m}^{-2}\right)$.

$\mathrm{R}=$ Rebaixamento da superfície $(\mathrm{mm})$.

Ds=Densidade do material $\left(\mathrm{g} \mathrm{cm}^{-3}\right)$.

Para se comparar as áreas influenciadas pelo pastoreio e as áreas onde tal efeito é nulo, realizou- -se mensurações de perfil/seção transversal, sobre 10 pontos do canal, onde cujos pontos se encontravam próximos e nas mesmas condições das áreas onde nota-se a presença do gado, embora os locais selecionados encontravam-se isentos dos efeitos do pastoreio. Assim, obteve-se uma média da largura e profundidade do canal nestas áreas.

\section{RESULTADOS}

\section{Aspectos Físicos do solo das margens}

Buscou-se avaliar a diferença nas características físicas do solo (resistência, densidade aparente e porosidade total) em áreas com e sem o efeito do pastoreio. Verificou-se significativa diferença entre as áreas avaliadas (Quadro 1). Obteve-se nas 90 amostras coletadas em áreas com efeito, uma média de resistência de $1,86 \mathrm{kgf} / \mathrm{cm}^{2}$, enquanto que nas 90 amostras coletadas em margens onde não ocorre efeito do pastoreio a resistência do solo apresentou uma média de $0,66 \mathrm{kgf} / \mathrm{cm}^{2}$, mostrando assim, que nas áreas de pastagem o solo se apresenta bem mais resistente do que nas áreas onde não ocorre tal atividade. Além disso, a variação amostral foi menor na área de travessia do gado. 
Avaliação dos efeitos do pastoreio sobre a erosão em margens de canal fluvial em sistema de faxinal Wolliver Anderson Dias, Edivaldo Lopes Thomaz

\begin{tabular}{|l|c|c|}
\hline Parâmetros Físicos do solo de margens & Com pastoreio & Sem pastoreio \\
\hline Resistência $\left(\mathrm{kgf} / \mathrm{cm}^{2}\right)$ & ${ }^{1} 1,86 \pm 0,83 \mathrm{a}$ & $0,66 \pm 0,44 \mathrm{~b}$ \\
\hline Densidade do solo $\left(\mathrm{g} / \mathrm{cm}^{3}\right)$ & $1,10 \pm 0,07 \mathrm{a}$ & $0,94 \pm 0,11 \mathrm{~b}$ \\
\hline Porosidade total $(\%)$ & $58,35 \pm 2,59 \mathrm{a}$ & $64,34 \pm 4,02 \mathrm{~b}$ \\
\hline
\end{tabular}

${ }^{1}$ média e desvio padrão. Letras iguais na mesma linha não apresentam diferença significante ao nível de $5 \%$ pelo Teste t.

Quadro 1: Características físicas do solo em áreas com e sem efeito de pastoreio

Verificou-se também diferença entre a densidade e porosidade do solo nas margens com e sem efeito do pastoreio. Nas áreas onde há ocorrência de travessia do gado de uma margem a outra do canal, o solo se apresenta com maior densidade e menor porosidade em relação às áreas onde não há travessia do gado (Quadro 1).

Conclui-se que nas margens do canal onde ocorre o pastoreio, o solo encontra-se mais compactado, denso e com menor porosidade. Assim, a erosão nestas áreas ocorre não somente devido ao desmoronamento das margens causado pelo gado (efeito direto), mas também pela dificuldade de infiltração das águas da chuva, que com o escoamento superficial removem e transportam grande volume de sedimentos para dentro do canal (efeito indireto). Nos ensaios com penetrômetro de bolso detectou-se melhor as diferenças físicas do solo entre as duas áreas, em comparação a técnica de anel volumétrico (amostras indeformadas).

Comparações dos aspectos físicos do solo entre áreas com e sem efeito do pastoreio na Bacia do Rio Guabiroba foram realizadas também por Thomaz e Homiak (2002) e Thomaz (2005). Os efeitos nas vertentes (terras altas) matem o mesmo padrão que nas margens dos rios, isto é, as áreas de pastoreio diferem das áreas não utilizadas com pastagens. A densidade aparente superficial foi $21 \%$ superior, enquanto que a porosidade total foi $18 \%$ inferior nos locais de pastagens. A resistência superficial foi 2,8 vezes superior nas pastagens. Por fim, a taxa de infiltração final foi 8 vezes inferior na área com pastagem. De modo contrário, o escoamento superficial mostrou-se bem maior nas áreas com pastagens (THOMAZ; DIAS, 2009).

\section{Monitoramento da erosão}

Ao longo do período de monitoramento das seções, monitorou-se também a precipitação no local. A precipitação foi mensurada a partir de um pluviômetro instalado nas proximidades da área.

A partir dos dados primários coletados em campo, constatou-se que ao longo do período de realização do monitoramento, os índices pluviométricos anuais apresentaram-se abaixo da média e até mesmo da mínima histórica (entre os anos de 1976 e 2000) do município de Guarapuava. A precipitação pluviométrica anual em Guarapuava, entre os anos de 1976 e 2000, apresentou uma média de $1961 \mathrm{~mm}$. Os anos de 1983 (3168,4 mm) e 1998 (2456,6 mm) foram os mais chuvosos e os anos de 1985 (1262,1 $\mathrm{mm}$ ) e 1988 (1308 mm) os mais secos (THOMAZ; VESTENA, 2003).

De acordo com o pluviômetro instalado na área, entre agosto de 2006 à dezembro de 2008 (28 meses), foram registrados 202 eventos de precipitação, os quais somam juntos um total de 3100,8 $\mathrm{mm}$, menos que o total já registrado em um único ano (1983) no município de Guarapuava. O ano de 2007 registrou um total de $1268 \mathrm{~mm}$ acumulados de chuva, enquanto que o ano de 2008 somou um total de $1282 \mathrm{~mm}$. No que diz respeito à média mensal de precipitação, o ano de 2007 apresentou uma média de $105,73 \pm 76,27 \mathrm{~mm}$ e o ano de 2008 uma média de $106,88 \pm 65,89$. Os altos valores de desvio padrão que acompanham as médias indicam a variação da pluviosidade entre os meses do ano, desta forma no ano de 2007 o mês com maior índice pluviométrico foi maio, com $230 \mathrm{~mm}$, enquanto que o menor índice foi registrado em agosto, com apenas $6 \mathrm{~mm}$, para tal ano a variação da precipitação entre o mês mais 
chuvoso, maio ( $230 \mathrm{~mm}$ ) e o menos chuvoso, agosto (6 mm), resultou em uma amplitude de $224 \mathrm{~mm}$. O ano de 2008 por sua vez, apresentou o mês mais chuvoso ao longo do experimento, outubro (259,5 $\mathrm{mm}$ ), divergindo do ano anterior (2007), maio foi o mês com menor índice de precipitação (39 mm) assim, em 2008 a amplitude conseqüente da variação entre o mês mais chuvoso e o menos chuvoso foi de $220,5 \mathrm{~mm}$. Ressalta-se que o pluviômetro instalado na Bacia do Rio Guabiroba encontra-se a aproximadamente $13 \mathrm{~km}$ do município de Guarapuava, portanto, a distância entre os pluviômetros permite uma possível variabilidade entre os dados de um e outro.
Nas 3 seções instaladas em margens do canal onde ocorre o efeito do pastoreio, com o objetivo de estabelecer comparação com as áreas onde não ocorre tal efeito, devido ao monitoramento sistemático, foi possível quantificar a evolução das formas do canal levando em consideração a remoção e acumulo de material.

O monitoramento contou com 7 mensurações em cada uma das seções, sendo a primeira em agosto de 2006 (início do monitoramento) e a última em dezembro de 2008 (término do monitoramento). No quadro abaixo (Quadro 2) observa-se a mobilização/ remoção do solo ao longo dos 28 meses de monitoramento nas três seções avaliadas.

\begin{tabular}{|c|c|c|c|c|c|c|c|c|}
\hline seção & $\begin{array}{c}\text { Numero } \\
\text { de } \\
\text { pontos }\end{array}$ & $\begin{array}{l}\text { Pontos } \\
\text { com } \\
\text { remoção }\end{array}$ & $\%$ & $\begin{array}{c}\text { Pontos } \\
\text { com } \\
\text { acúmulo }\end{array}$ & $\%$ & $\begin{array}{c}\text { Balanço } \\
\text { global* } \\
(\mathrm{cm})\end{array}$ & $\mathrm{kg} / \mathrm{m}^{2}$ & $\begin{array}{c}\text { Mobilização } \\
\text { total na } \\
\text { parcela (kg) }\end{array}$ \\
\hline $1\left(70 m^{2}\right)$ & 88 & 18 & 20,45 & 70 & 79,55 & $2,83 \pm 6,5$ & 31,13 & 2179,1 \\
\hline $2\left(36 m^{2}\right)$ & 49 & 10 & 20,41 & 39 & 79,59 & $2,53 \pm 9,91$ & 27,83 & 1001,88 \\
\hline $3\left(96 m^{2}\right)$ & 117 & 47 & 40,17 & 70 & 59,83 & $\begin{array}{c}-2,77 \\
\pm 14,26\end{array}$ & $-30,47$ & $-2925,12$ \\
\hline
\end{tabular}

Nota: *balanço global significa a média de rebaixamento ou acumulo considerando-se todos os pontos avaliados acompanhados de desvio padrão.

Quadro 2: Síntese da mobilização/remoção do solo nas seções monitoradas entre agosto/2006 à dezembro/2008

Conhecendo-se previamente a densidade aparente do solo das margens onde foram instaladas as seções $\left(1,1 \mathrm{~g} / \mathrm{cm}^{3}\right)$ (DIAS; THOMAZ, 2007), estimou-se a retirada ou acúmulo de material em cada uma delas ao longo do período monitorado. Ao todo foram mensurados na rede de perfis transversais repetidos, 3 seções, sendo que na primeira foram mensurados 88 pontos dos quais $18(20,45 \%)$ apresentaram remoção de material (rebaixamento) enquanto que os outros 70 pontos $(79,55 \%)$ registraram acumulo de material, o balanço global dessa seção foi de $2,83 \mathrm{~cm}$, resultando num acúmulo de $31,13 \mathrm{~kg} / \mathrm{m}^{2}$, assim, considerando a área total da seção $\left(70 \mathrm{~m}^{2}\right)$, estimou-se um acúmulo de $2179,1 \mathrm{~kg}$. Na segunda seção, onde foram mensurados 49 pontos, dos quais 10 pontos $(20,41 \%)$ registraram rebaixamento, enquanto 39 pontos $(79,59 \%)$ apre- sentaram acúmulo de material, o balanço global da mobilização desta seção foi de $2,53 \mathrm{~cm}$, ou seja, o acumulo superou novamente a remoção de material no interior da seção no período monitorado, o acumulo foi de $27,83 \mathrm{~kg} / \mathrm{m}^{2}$. Portanto, em toda a seção $\left(36 \mathrm{~m}^{2}\right)$ foram mobilizados em torno de 1001,88 $\mathrm{kg}$ de solo. Na terceira seção, foram mensurados 117 pontos, sendo que 47 deles $(40,17 \%)$ apresentaram remoção de material, de modo que os outros 70 pontos $(59,83 \%)$ apresentaram acúmulo. Nesta seção o balanço global registrou $-2,77 \mathrm{~cm}$, equivalendo a uma perda de material de $30,47 \mathrm{~kg} / \mathrm{m}^{2}$, o que representa no total da seção $\left(96 \mathrm{~m}^{2}\right)-2925,12 \mathrm{~kg}$ (Quadro 2).

Com os dados obtidos, pode-se perceber que nas seções 1 e 2, ocorreu uma significativa remobilização de material, em taxas relativamente próximas 
(Quadro 2), a análise dos dados somada as observações de campo, permitiram constatar que nestas seções o material remobilizado no seu interior é oriundo das margens sendo removido pelo desmoronamento ocasionado pelo gado nos momentos de travessia de uma margem a outra (efeito direto), ou mesmo por deposição de sedimentos da encosta (efeito indireto).

A partir dos dados obtidos, pode-se confeccionar representações do terreno entre o início e o término do monitoramento (Figura 3). Com as imagens observou-se a evolução geomorfológica do interior de cada uma das seções avaliadas.

A influencia do pastoreio nas zonas ripárias é também apresentada por Trimble e Mendel (1995), como responsável por diminuir a resistência a erosão, devido a redução da vegetação, expondo maior vulnerabilidade ao substrato.
Neste caso, o material removido das margens (pontos com remoção) deposita-se no canal (Pontos de remobilização/deposição) (principalmente no centro da seção), assim, devido a ineficiência do fluxo no transporte dos sedimentos depositados, inicia-se o processo de remodelagem da paisagem fluvial, seja por feições erosivas ou de deposição que evoluem para o assoreamento do canal.

Embora o processo de entrada de sedimento das margens no interior do canal fluvial predomine nas 3 seções avaliadas, a seção número 3 comportou-se de forma contrária as anteriores, pois enquanto as duas primeiras apresentaram significativa deposição de sedimentos por $\mathrm{m}^{2}$ a seção 3 apresentou remoção, chegando a perder quase 3 toneladas de solo $(-2925,12$ kg) (Quadro 2).

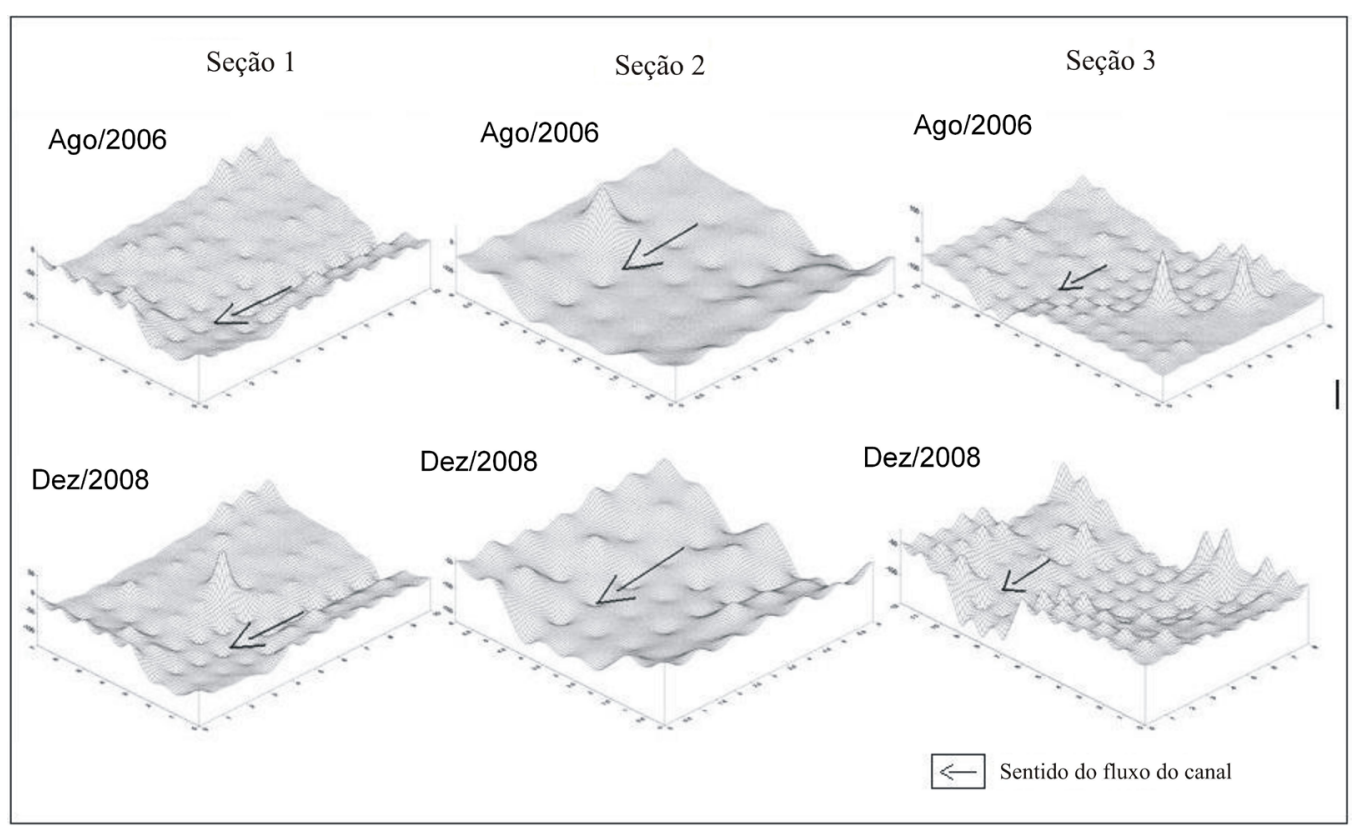

Figura 3: Representação digital do terreno das três seções monitoradas (margens afetadas pelo gado) no início e no término do experimento.

A maior ou menor taxa de remobilização ou remoção de solo apresentada pelas seções avaliadas caracteriza a dinâmica expressada pela relação entre a atividade de pastagem sobre os aspectos geomorfológicos de tais áreas, não sendo elas suficientes para afirmar a relação direta entre a deposição ou remoção exata de solo ao longo das seções, pois trata -se de um sistema aberto que dispõe de uma complexa dinâmica, recebendo energia e matéria de outros sistemas. Tal relação pode ser constatada através da relação de deposição de materiais da encostas nos canais fluviais e pela dinâmica do canal influenciando nas áreas avaliadas. Portanto, é cabível ressaltar que a seção 3 localiza-se a jusante das anteriores, dispondo assim 
de maior energia e volume de água e assim, maior competência no transporte de materiais.

Com o monitoramento realizado no interior das seções pode-se observar a dinâmica da movimen- tação do solo das margens ao longo dos intervalos temporais entre as mensurações (Quadro 3).

\begin{tabular}{|c|c|c|c|c|}
\hline \multirow{2}{*}{$\begin{array}{l}\text { Intervalos entre as } \\
\text { mensurações }\end{array}$} & \multirow{2}{*}{ Precipitação (mm) } & \multicolumn{3}{|c|}{ Remobilização/Remoção de solo (kg) } \\
\hline & & Seção 1 & Seção 2 & Seção 3 \\
\hline $\begin{array}{c}1(08 / 2006- \\
12 / 2006)\end{array}$ & 436 & 1293,6 & $-506,88$ & $-1531,2$ \\
\hline $\begin{array}{c}2(12 / 2006- \\
04 / 2007)\end{array}$ & 598,5 & -308 & 1845,36 & 3569,28 \\
\hline $\begin{array}{c}3(04 / 2007- \\
08 / 2007)\end{array}$ & 385,3 & $-862,4$ & $-1421,64$ & $-2544,96$ \\
\hline $\begin{array}{c}4(08 / 2007- \\
12 / 2007)\end{array}$ & 332 & 2186,8 & 59,4 & $-496,32$ \\
\hline $\begin{array}{c}5(12 / 2007- \\
05 / 2008)\end{array}$ & 488 & 1378,3 & 1136,52 & $-2006,4$ \\
\hline $\begin{array}{c}6(05 / 2008- \\
12 / 2008)\end{array}$ & 861 & 1247,4 & 2158,2 & 95,04 \\
\hline
\end{tabular}

Quadro 3: Dinâmica da mobilização/remoção do solo em cada seção entre os intervalos de monitoramento da erosão

No primeiro intervalo, onde o total da precipitação foi de $436 \mathrm{~mm}$ a seção 1 registrou uma mobilização de $1293,6 \mathrm{~kg}$, enquanto que a seção 2 e 3 apresentam remoção de material, $-506,88 \mathrm{~kg}$ e $-1531,2 \mathrm{~kg}$ sucessivamente. Já no segundo intervalo, embora o total da precipitação apresentará -se superior ao apresentado no intervalo anterior $(598,5$ $\mathrm{mm})$ apenas a seção 1 apresentou remoção (-308 $\mathrm{kg}$ ), a seção 2 por sua vez mobilizou 1845,36 kg e a seção 3, 3569,28 kg de solo. No terceiro intervalo a precipitação foi de ordem inferior a dos intervalos anteriores $(385,3 \mathrm{~mm})$, porém nesta ocasião as 3 seções avaliadas apresentaram remoção de material: seção $1(-862,4 \mathrm{~kg})$, seção $2(-1421,64 \mathrm{~kg})$ e seção 3 $(-2544,96 \mathrm{~kg})$. O quarto intervalo foi o período em que se registrou o menor total de precipitação ao longo do monitoramento ( $332 \mathrm{~mm})$, neste intervalo a seção 1 mobilizou $2186,8 \mathrm{~kg}$, a seção 2 mobilizou $59,4 \mathrm{~kg}$, por outro lado na seção 3 a remoção foi de $(-496,32)$. A precipitação resultante do quinto intervalo foi de $488 \mathrm{~mm}$, neste intervalo, foram mobilizados na seção 1, 1378,3 kg de solo, na seção 2, 1136,52 kg e na seção 3 uma remoção de $-2006,4 \mathrm{~kg}$. O último intervalo avaliado, foi também o maior deles, e por sua vez apresentou também o maior total de precipitação $(861 \mathrm{~mm})$, neste intervalo, todas as seções apresentaram mobilização de material, a seção 1 mobilizou $1247,4 \mathrm{~kg}$, a seção 2 apresentou uma mobilização de $2158,2 \mathrm{~kg}$ e por fim a seção 3 mobilizou 95,4kg de solo (Quadro 3).

Com o monitoramento detalhado pode-se perceber a grande dinâmica da movimentação de sedimentos no interior das seções avaliadas, enquanto que às margens isentas de efeitos do gado e com presença de cobertura vegetal, apresentam sensíveis mudanças. A desuniformidade e ausência de padronização na manifestação dos dados obtidos nos intervalos, quando relacionados com a precipitação, indica a interrelação entre o impacto do gado sobre ás margens, representado pelo desmoronamento das mesmas (efeito direto), e às taxas de escoamento das encostas somado aos índices pluviométricos e a dinâmica do canal fluvial. 


\section{Erosão e geometria do canal}

As mudanças geométricas do canal ao longo do experimento também indicam a evolução das formas, contribuindo para a avaliação da influencia do pastoreio na aceleração dos processos geomorfológicos. Nos parâmetros geométricos comparados entre as margens que sofrem impactos do gado (pontos de travessia) e aquelas que não sofrem tal impacto, constatou-se significativa diferença. Na obtenção dos valores médios da profundidade de cada seção, descontou-se a altura das estacas que formavam o quadro planimétrico $(45 \mathrm{~cm})$, com exceção da seção 2 que a altura descontada foi $24,5 \pm 24,41 \mathrm{~cm}$ (média entre a altura das 4 estacas que formavam o quadro), destaca-se que nesta seção à altura das estacas eram diferentes devido as irregularidades do terreno. $\mathrm{Na}$ seção 1 a largura do canal foi estimada em 7 metros com profundidade média de $13,77 \pm 25,75 \mathrm{~cm}$ (n 88), na seção 2 (Figura 4) a largura estimada para o canal atingiu $6 \mathrm{~m}$, com profundidade de $56,56 \pm 36,81 \mathrm{~cm}$ (n 49), e por fim na seção 3 o canal foi estimado em 12 metros de largura com profundidade média de
40,2 $\pm 27,05$ cm (n 117). Em relação a geometria do canal (forma), verificou-se que nas margens não afetados pela travessia do gado a largura média do canal foi de $1,51 \pm 18,53 \mathrm{~m}$ (n 10) e profundidade média de $69,33 \pm 18,77 \mathrm{~cm}$ (n 151), (Figura 5).

Na comparação entre os trechos do canal alterados pelo efeito do pastoreio em relação as margens plenas, observa-se que na primeira seção a largura do canal apresenta-se 4,6 vezes superior, já na segunda seção as taxas de largura superam em 3,97 vezes a largura média dos trechos onde as margens não sofrem efeitos, a terceira seção por sua vez apresentou as maiores taxas de largura em relação as margens plenas, chegando a aproximadamente 8 vezes a largura das margens isentas do efeito do gado.

No que diz respeito à profundidade entre os trechos do canal monitorado nas áreas com e sem efeito do gado, a primeira seção foi a que registrou a maior diferença em relação aos trechos de margens plenas, apresentando uma profundidade 5,03 vezes inferior, já as seções 2 e 3 apresentaram profundidades de 1,22 e 1,72 vezes respectivamente menor em relação a tais margens (margens sem efeito do gado).

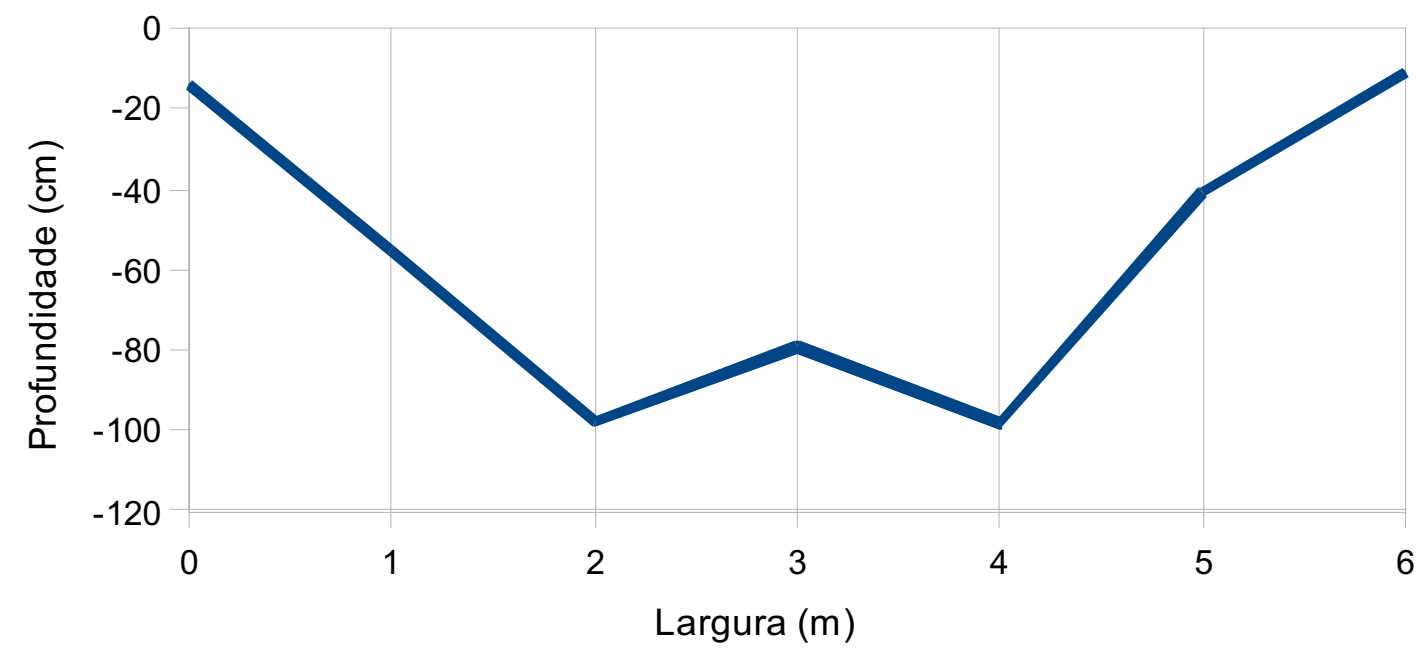

Figura 4: Exemplo de perfil transversal em local de travessia de gado (seção 2) 


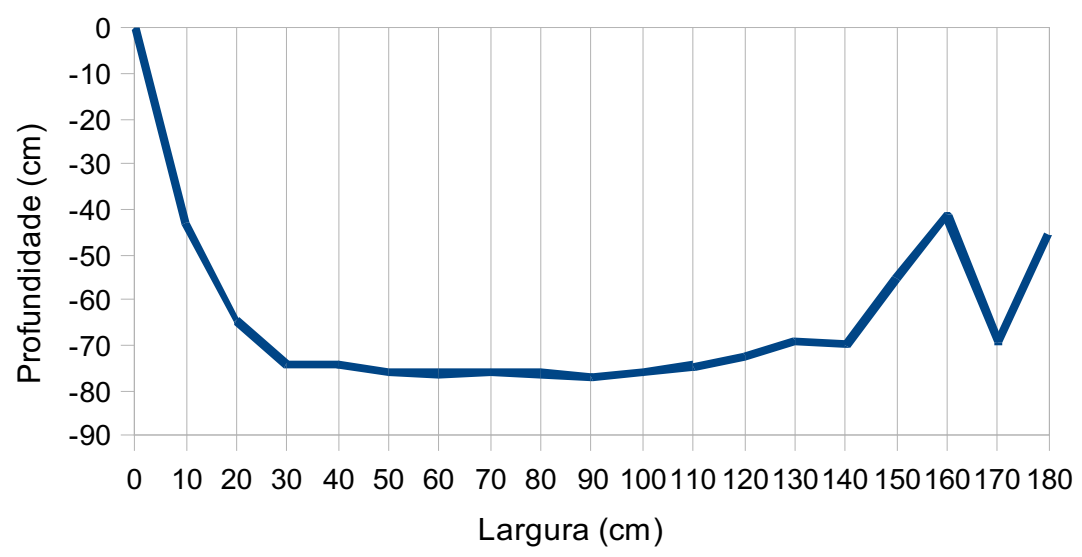

Figura 5: Perfil transversal médio de áreas onde não ocorre a travessia do gado (margens plenas)

$\mathrm{O}$ efeito do pastoreio sobre a geometria de canais também foi descrito por Trimble (1994). O autor afirma que em locais sem controle de pastoreio a erosão de margem foi de 3 a 6 vezes superior comparado com locais onde houve medidas de controle. A erosão de margens em área de pastagens atingiu 40 $\mathrm{m}^{3} / \mathrm{km} / \mathrm{ano}$.

Deste modo, a geometria do canal indica uma mudança nas feições geomorfológicas apresentadas pelas margens, que se relacionam diretamente com a influência do pastoreio sobre estas áreas. Com os perfis transversais apresentados acima, pode-se evidenciar significativas diferenças entre os pontos de travessia do gado em comparação com os setores não afetados. Nos locais de travessia o canal apresentou-se mais aberto (largo) e raso, enquanto que nos locais sem travessia de gado (margens plenas) o canal foi mais estreito e profundo.

As observações de campo, bem como as mensurações das seções transversais dos locais não afetados pelo gado, indicam que há pouca influência na entrada de sedimentos em margens não afetadas pelo pastoreio do gado, por outro lado, o processo ocorre inversamente nos pontos de travessia.

\section{CONSIDERAÇÕES FINAIS}

Com o experimento conduzido pode se constatar que as atividades de pastoreio em sistema de Faxinal influenciam de forma considerável tanto na geomorfologia de encostas quanto na geomorfologia fluvial e por extensão na dinâmica dos rios.

As áreas ripárias utilizadas para pastoreio apresentam maior sensibilidade frente aos processos erosivos, pois o gado remove a vegetação das margens, eliminando assim a função de filtro exercida pela vegetação, tornando mais freqüente a deposição de sedimentos oriundos da encosta no interior dos riachos (conectividade encosta/canal fluvial).

Os efeitos diretos do gado sobre as zonas ripárias são evidenciados de forma significativa. Tal atividade acelera diretamente os processos erosivos nas margens dos rios. Os efeitos sobre as margens foram indicados pela maior densidade, resistência e menor porosidade dos solos em relação ao solo das margens não afetadas, refletindo em maiores taxas de erosão nestas áreas. As análises geométricas do canal também comprovaram a influencia do gado sobre as margens, de modo que nas áreas de pastagens o canal apresenta-se mais largo e raso (assoreamento) quando comparado com as áreas isentas do efeito do gado (zona ripária preservada). Outro fator de destaque é a remoção de solo das margens por desbarrancamento, ocorrente principalmente nos momentos de travessia do gado de uma margem a outra do canal.

Observa-se que nas áreas influenciadas pelo pastoreio (seções avaliadas) ocorre uma intensa dinâmica da movimentação de sedimentos, seja no âmbito de remoção ou deposição de materiais, enquanto que nas margens plenas tal dinâmica foi insignificante. 
Outro fenômeno observado foi à entrada de escombros lenhosos no interior do canal conseqüente do pastoreio em meio à vegetação (sistema de faxinal), gerando depósitos e barragens no interior do canal. Estes depósitos de escombros (folhas, galhos e troncos) por sua vez, dão origem a eficientes barragens que barram parcial ou totalmente a passagem de sedimentos de fundo, contribuindo de forma notável para a erosão e sedimentação, estes detritos quando apresentam diâmetro superior a $10 \mathrm{~cm}$ recebe por alguns autores, entre eles Swanson \& Lienkaemper (1978) o nome de grandes detritos orgânicos (GDO) (FERNANDEZ, 2003). Os depósitos de escombros que formam-se no interior dos canais influenciam significativamente na dinâmica fluvial. A alteração na eficiência do fluxo é dada pelo aparecimento de obstáculos, de modo que quanto mais lisa for a calha maior será a velocidade do fluxo (CUNHA, 2007).

Esse processo além de influenciar na geomorfologia de riachos, é importante também para a ecologia e biodiversidade, tendo em vista a alteração do ambiente ripário e a necessidade de readaptação de espécies frente ao novo ajuste do sistema. Assim, a influência da entrada destes detritos no leito dos rios merece atenção em futuros trabalhos.

\section{REFERÊNCIAS}

CUNHA, S. B. Geomorfologia Fluvial. In: GUERRA, A. T. G.; CUNHA, S. B. (Org.). GEOMORFOLOGIA: uma atualização de bases e conceitos. Rio de Janeiro: Bertrand Brasil, 7.ed. Cap. 5, p 211-252, 2007.

DIAS, W. A.; THOMAZ, E. L. Influência do pastoreio na mudança física do solo em margens de canal fluvial. In: XVI EAIC - ENCONTRO ANUAL DE INICIAÇÃO CIENTÍFICA. Anais... Maringá: UEM, 2007.

EMBRAPA. Manual de métodos de análise de solos. Rio de Janeiro, EMBRAPA/SNLCS, 1997.

EVANS, R. The erosional impacts of grazing animals. Progress in Physical Geography, 22 (2): p. 251-268, 1998.
FERNANDEZ, O. V. Q. O papel dos grandes detritos orgânicos na morfologia e sedimentologia em canais de cabeceira de drenagem. In: X Simpósio Brasileiro de Geografia Física Aplicada, Ano 2003, Rio de Janeiro, Anais... (CD-rom), Cidade Rio de Janeiro, 20, 2003.

FERREIRA, C. P.; CASATTI, L. Influência da estrutura do hábitat sobre a ictiofauna de um riacho em uma micro-bacia de pastagem, São Paulo, Brasil. Revista Brasileira de Zoologia, v 23, n. 3: p. 642-651, 2006.

FLORIANI, N.; CASSOL PINTO, M. L; LOMBARDI A. P.; STANISKI, A. e STRACHULSKI, J. Processos Erosivos no Subsistema "Terras de Plantar" em Faxinal Paranaense com Cultivo Moderno de Fumo Integrado. In: VIII SIMPÓSIO NACIONAL DE GEOMORFOLOGIA, Recife - PE, Setembro de 2010. Relação Morfogênese X Pedogênese, Anais ... Recife: UFPE, 1-16p, 2010.

LAWLER, D. M. The measurement of river bank erosion and lateral channel change: a review. Earth Surface Processes and Landforms, v. 18, p.777-821, 1993.

NAKAMURA, F.; YAMADA, H. Effects of pasture development on the ecological functions of riparian forests in Hokkaido in northern Japan. Ecological Engineering, 24, p. 539-550, 2005.

REICHARDT, K. A água em sistemas agrícolas. São Paulo: Monole, 1990.

STRAHLER, A. N. Quantitative analysis of watershed geomorphology. Transacions: American Geophysical Union, 38: p. 913-920, 1957.

THOMAZ, E. L. Processos hidrogeomorfológicos e o uso da terra em ambiente subtropical - Guarapu$a v a-P R$. São Paulo, 2005, 297 f. Tese (Doutorado em Ciência, área Geografia Física) - Faculdade de Filosofia Letras e Ciências Humanas, Universidade de São Paulo, 2005. 
THOMAZ, E. L.; HOMIAK, M. Ensaios de capacidade de infiltração de água em diferentes tipos de usos do solo na bacia do Rio Guabiroba, Guarapuava, PR. UNICENTRO: Guarapuava. Relatório de iniciação cientifica. 2002.

THOMAZ, E. L. \& VESTENA, L. R. Aspectos Climáticos de Guarapuava-PR. Guarapuava: UNICENTRO, 2003.

THOMAZ, E. L.; LUIZ, J. C. Mensuração de remoção do solo entre ravinas por meio de técnica dinâmica e volumétrica. In: SIMPÓSIO NACIONAL DE GEOMORFOLOGIA E I ENCONTRO SUL-AMERICANO DE GEOMORFOLOGIA, 5, Santa Maria, agosto de 2004. Geomorfologia e Riscos Ambientais, Anais... Santa Maria: UFSM, 2004.p.1-14

THOMAZ, E. L.; DIAS, W. A. Bioerosão - Evolução do Rebanho Bovino Brasileiro e Implicação nos
Processos Geomorfológicos. Revista Brasileira de Geomorfologia. v.10, n.2, p. 3-11, 2009.

TRIMBLE, S. W. Erosional effects o cattle on streambanks in Tennesee, U.S.A. Earth Surface Processes and Landforms, v 19: 451-464, 1994.

TRIMBLE, S. W.; MENDEL, A. C. The cow as a geomorphic agent: a critical review. Geomorphology. v. 13: p. $233-253,1995$.

WOHL, N. E. \& CARLINE, R. F. Relations among riparian grazing, sediment loads, macroinvertebrates, and fishes in three central Pennsylvania streams. $\mathrm{Ca}$ nadian Journal of Fisheries And Aquatic Sciences, Ottawa, v 53: p. 260-266, 1996. 